\title{
INVESTIGATION INTO FATIGUE BEHAVIOUR OF METAL-COMPOSITE GLUE CONNECTION
}

\author{
Mirosław Rodzewicz \\ Warsaw University of Technology, Poland
}

\begin{abstract}
The paper presents the results of experimental investigations into fatigue properties of metal and CFRP-composite glued joints. The object of investigation was adhesive joints between metal sheets made from iron alloy 30HGS (popular steel in the Polish aviation industry) and CFRP orthogonal reinforced sheets made from 10 layers of SIGRATEX CE3208 pre-preg. The main adhesive was the WK-3 glue (applied in the form of $0.2 \mathrm{~mm}$ thin foil) while the DP-490 - liquid epoxy glue was used as technological aid for specimen manufacturing. Two kinds of specimens were prepared and tested: single-lap joints and double-lap joints. The paper presents $S$ - $N$ curves for both kinds of those specimens. Besides fatigue life of the glued joints, the interest was focused on the NDT tests regarding damage propagation inside the glue-connection. The paper presents several $C$-scans made at different stages of fatigue testing. It has been found that the damage occurs almost equally in the whole volume of the glue layer (contrary to the expectation following from the physical model of the glue-connection internal loading). The results of experiments regarding thermal effect of cyclic loading of the glued joints are also described. It has been found that this effect could be used as an important parameter for diagnostics purposes of the glued joints.
\end{abstract}

\section{INTRODUCTION}

As it is well-known, glue (or adhesive) connections are quite common in aeronautical structures. This work presents the results of the investigations of two kinds of glued joints between the steel sheet and CFRP-composite sheet (Fig.1):

- with a single lap

- and with a double lap.

The composite sheet consisted of 10 layers of SIGRATEX CE3208 carbon pre-pregs, with total thickness of $2.3 \mathrm{~mm}$. The steel sheet was iron alloy 30HGS, which is a very popular material in the Polish aviation industry. Two kinds of adhesives were used in the experiments: the basic adhesive was WK-3 - the glue made in Russia in the form of a thin foil of $0,2 \mathrm{~mm}$ thickness. This is a very strong adhesive, applied for example in the MI-2 helicopter blades. The supplementary adhesive which was used for specimens manufacturing was the epoxy glue DP-490 made by the 3M company. The dimensional parameters of the glued joints were: width $25 \mathrm{~mm}$ and length 12,5 (for single-lap) or $17 \mathrm{~mm}$ (for double-lap).

As it is well-known, glue (or adhesive) connections are quite common in aeronautical structures. This work presents the results of the investigations of two kinds of glued joints between the steel sheet and CFRP-composite sheet (Fig.1):

- with a single lap

- and with a double lap. 
The composite sheet consisted of 10 layers of SIGRATEX CE3208 carbon pre-pregs, with total thickness of $2.3 \mathrm{~mm}$. The steel sheet was iron alloy 30HGS, which is a very popular material in the Polish aviation industry. Two kinds of adhesives were used in the experiments: the basic adhesive was WK-3 - the glue made in Russia in the form of a thin foil of $0,2 \mathrm{~mm}$ thickness. This is a very strong adhesive, applied for example in the MI-2 helicopter blades. The supplementary adhesive which was used for specimens manufacturing was the epoxy glue DP-490 made by the 3M company. The dimensional parameters of the glued joints were: width $25 \mathrm{~mm}$ and length 12,5 (for single-lap) or $17 \mathrm{~mm}$ (for double-lap).

\section{MANUFACTURING THE SPECIMENS}

Figure 2 presents a the manufacturing process of the CFRP plate. The following key steps of the process are enumerated:

- preparing sheets of carbon-epoxy pre-pregs

- arranging the pre-preg layers

- curing on the press warmed up to $130^{\circ} \mathrm{C}$ and applying the pressure of 8 bars for 1 hour.

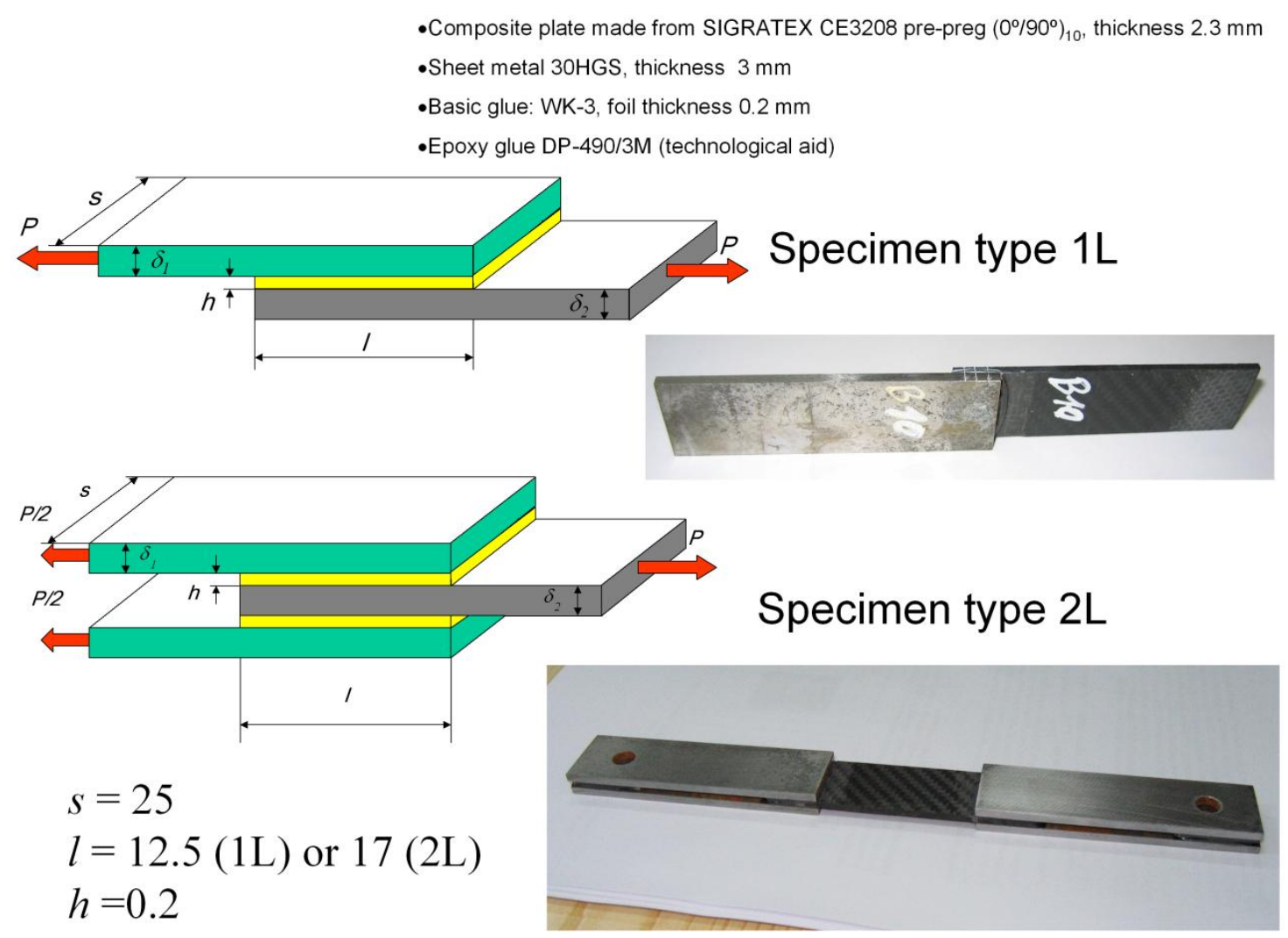

Fig. 1. Types of investigated specimens 


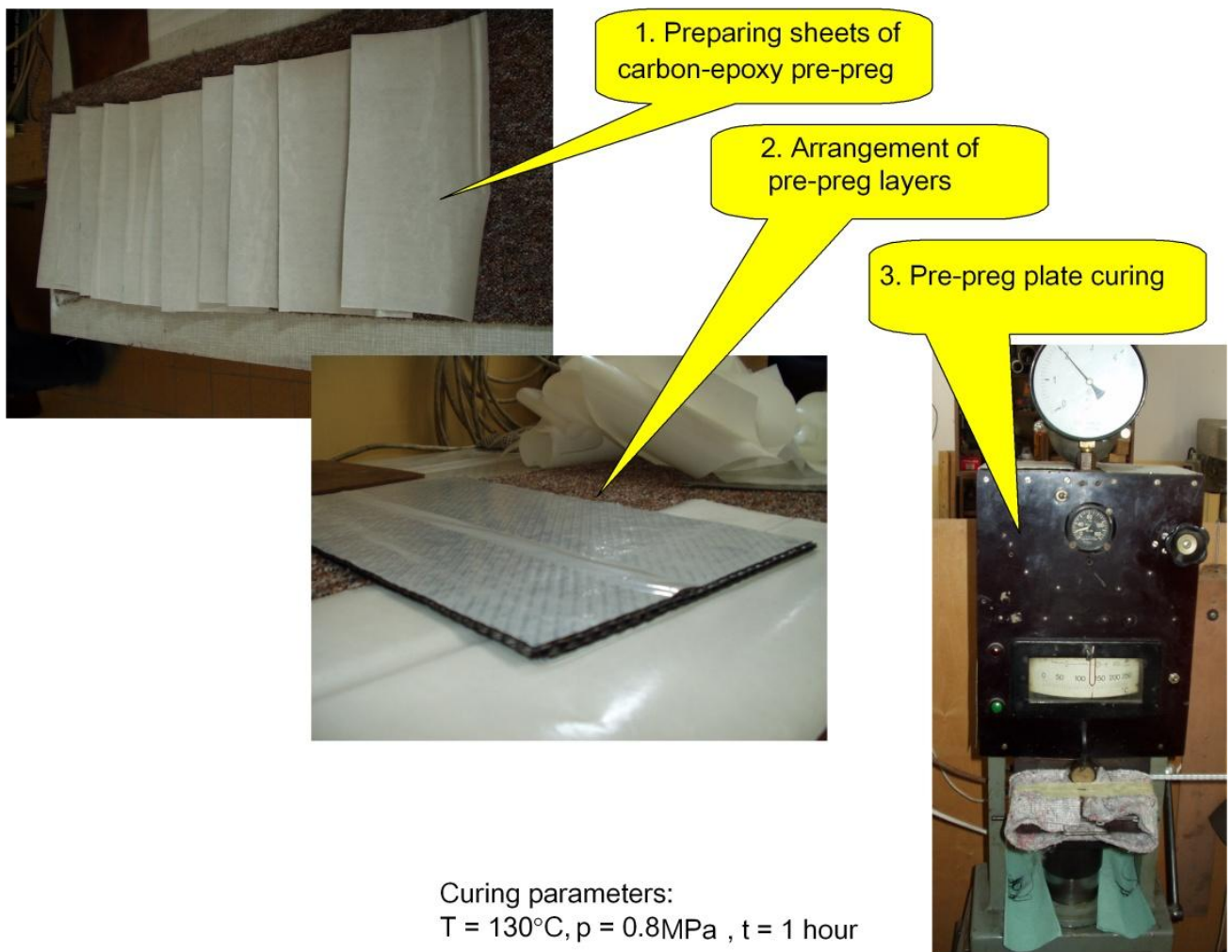

Fig. 2. CFRP pre-preg plate manufacturing process

The WK-3 adhesive needs more than $160 \mathrm{deg} \mathrm{C}$ for hardening so it is impossible to glue metal and composite at the same time as this temperature is critical for epoxy polymer. Therefore the process was divided into two stages: gluing and hardening the WK-3 adhesive on the metal sheets, and then gluing the composite sheets by means of an additional layer of liquid epoxy adhesive DP490. Figure 3 presents the process of gluing WK-3 adhesive on the surface of metal sheets. The parameters of this process were: $\mathrm{T}=165 \mathrm{deg} \mathrm{C}$, and pressure 10 bars for 1 hour. The process of integration of metal and epoxy sheets by use of DP-490 adhesive is illustrated by Fig. 4.
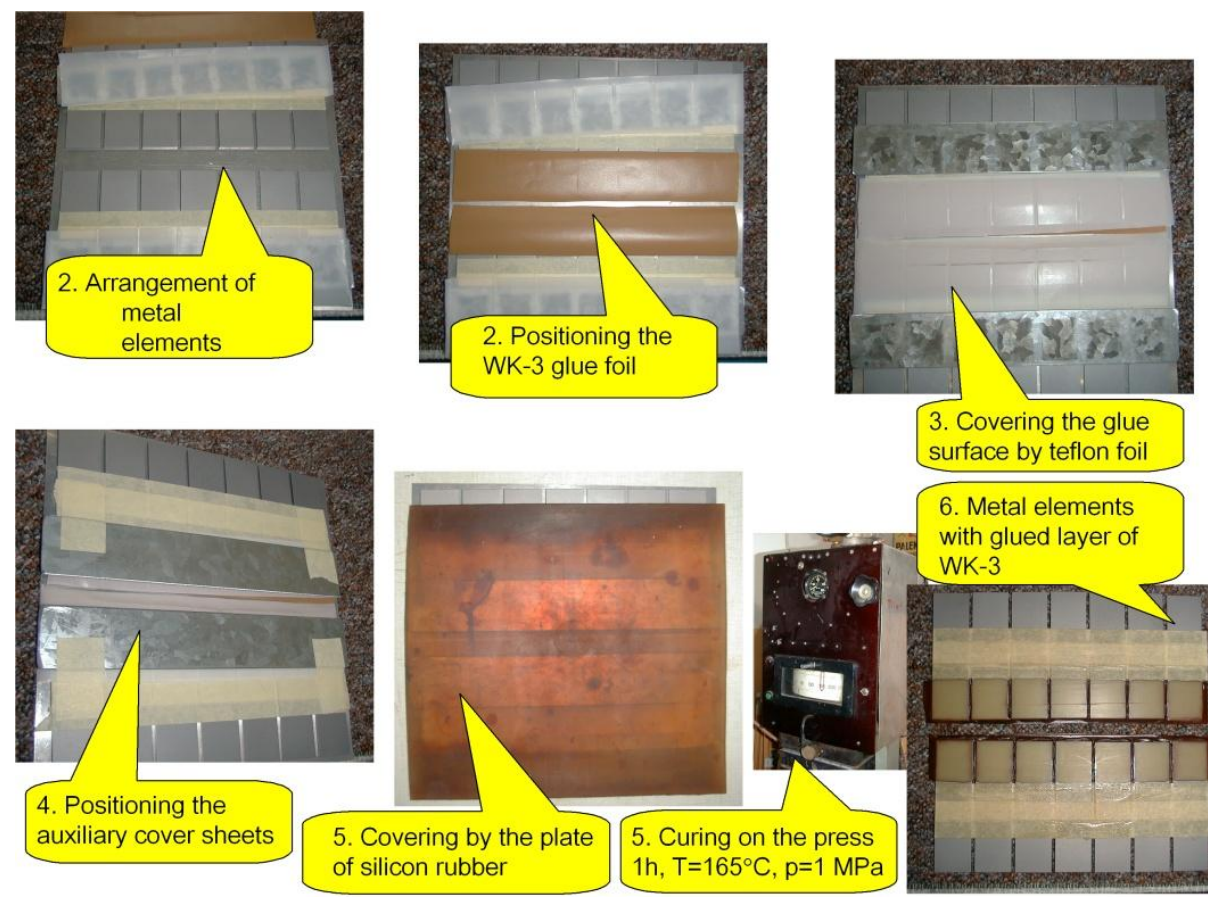

3. Covering the glue surface by teflon foil

6. Metal elements with glued layer of WK-3

Fig. 3. Manufacturing of the specimens -part 1/2 


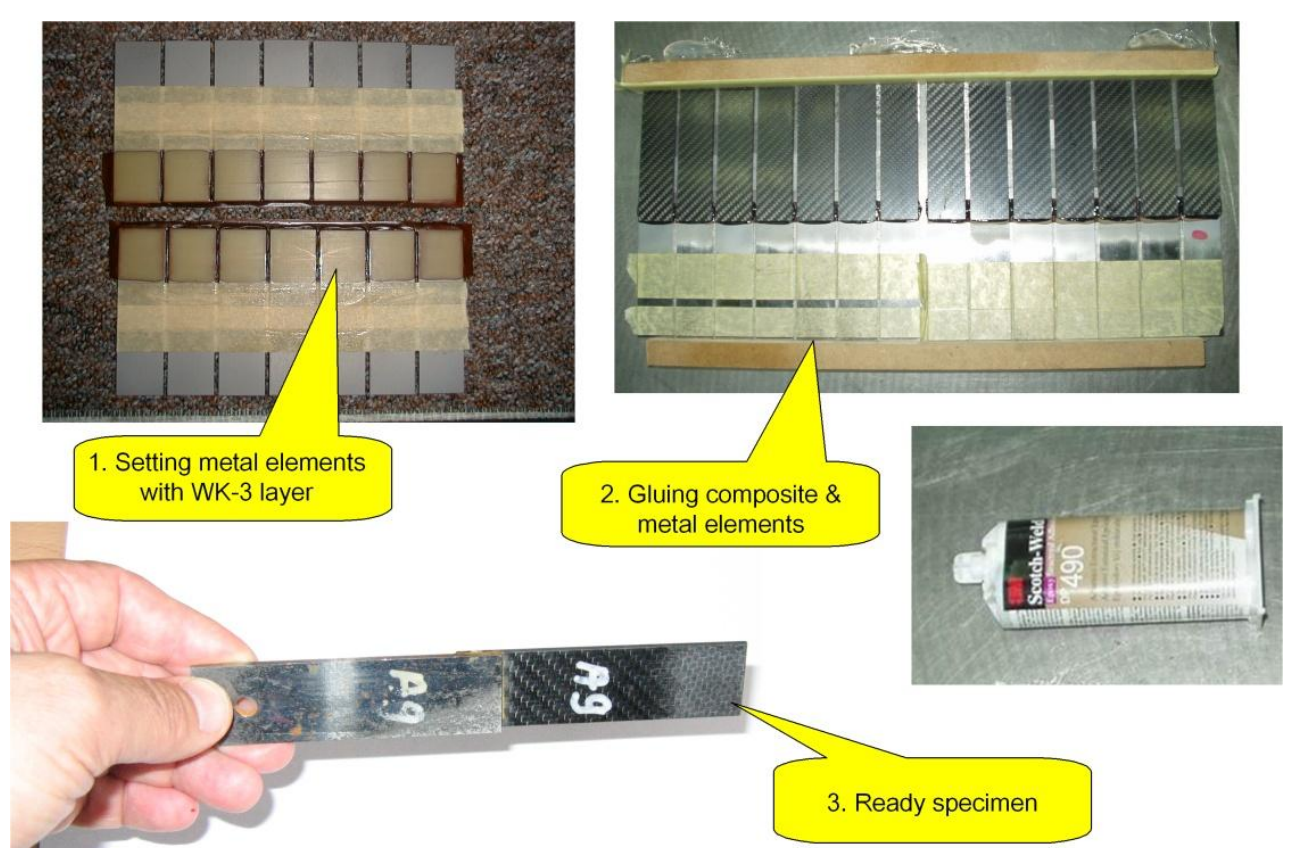

Fig. 4. Manufacturing of the specimens -part 2/2 


\section{FATIGUE and NDT TESTING}

Figures 5 and 6 present the fatigue devices. There were used two fatigue machines constructed at the Warsaw University of Technology. Both of them had the kinematical loading system, based on the adjustable eccentric mechanism with loading frequency of 750 cycles per minute. Normally, such loading frequency is too high for polymer composites (especially for GFRP composites), but it was checked before the tests that due to high thermal conductivity of carbon-epoxy composite the increase in specimen temperature during the fatigue test was at the acceptable level. The bigger machine was the WB-1 fatigue machine, which was applied for double lap specimens. The smaller one was WB-2, which was applied for single lap specimens.

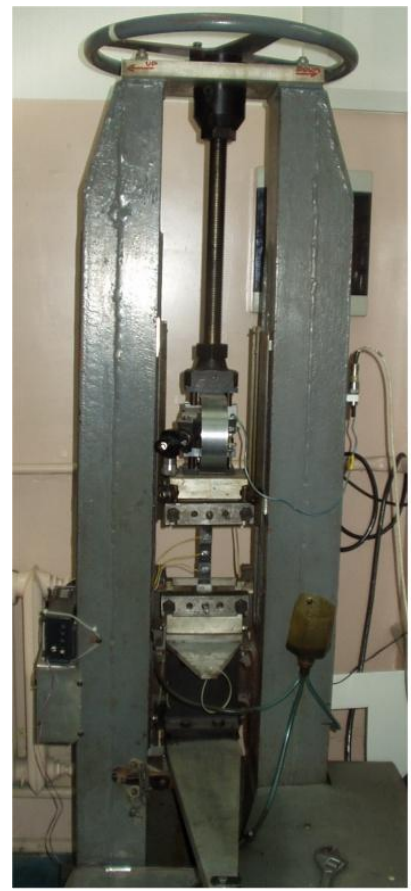

WB-1 fatigue machine

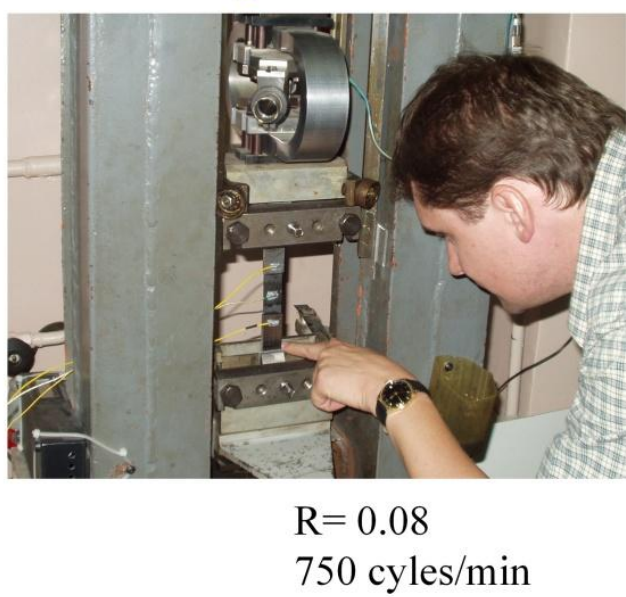

Fig. 5. Testing devices - part 1/2

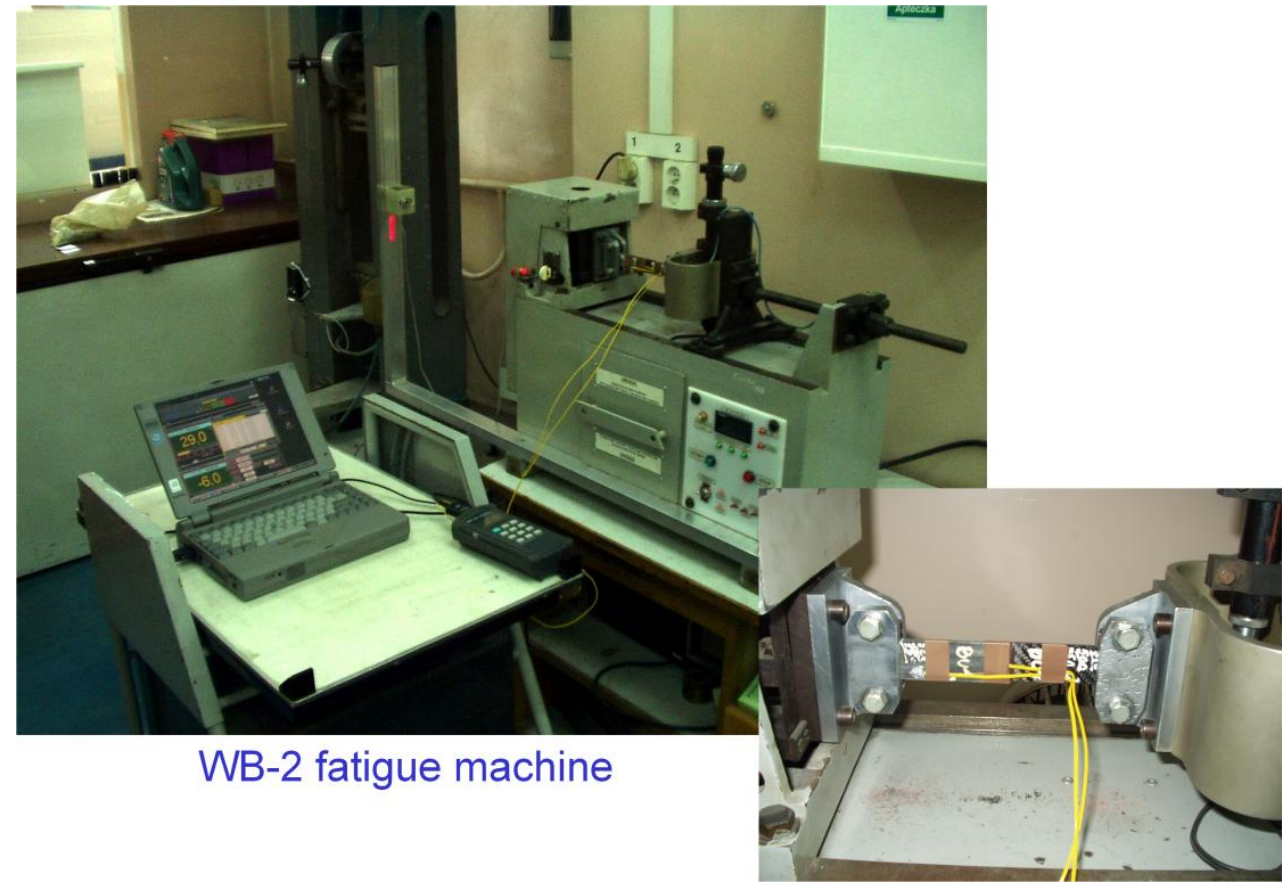

Fig. 6. Testing devices - part 2/2 
Figures 7 and 8 present the S-N curves as the main result of the fatigue investigations. On the left edges of the charts there are presented the results of the static strength tests. On the right edges there are presented the results of the residual strength tests after the fatigue tests, which were performed for some specimens. The dotted line marks the acceptable level of glue connection strength (which was derived on the basis of catalog data for some different structural adhesives). As it can be seen - in the case of the single lap glue connection we have a significant number of results under this red line. When it comes to the double lap glue connection, the status quo looks different. The reason for this is symmetrical loading, which produces only shear stress in the glue, while in the case of the single lap glue connection there are existing also forces tearing off the glued elements.

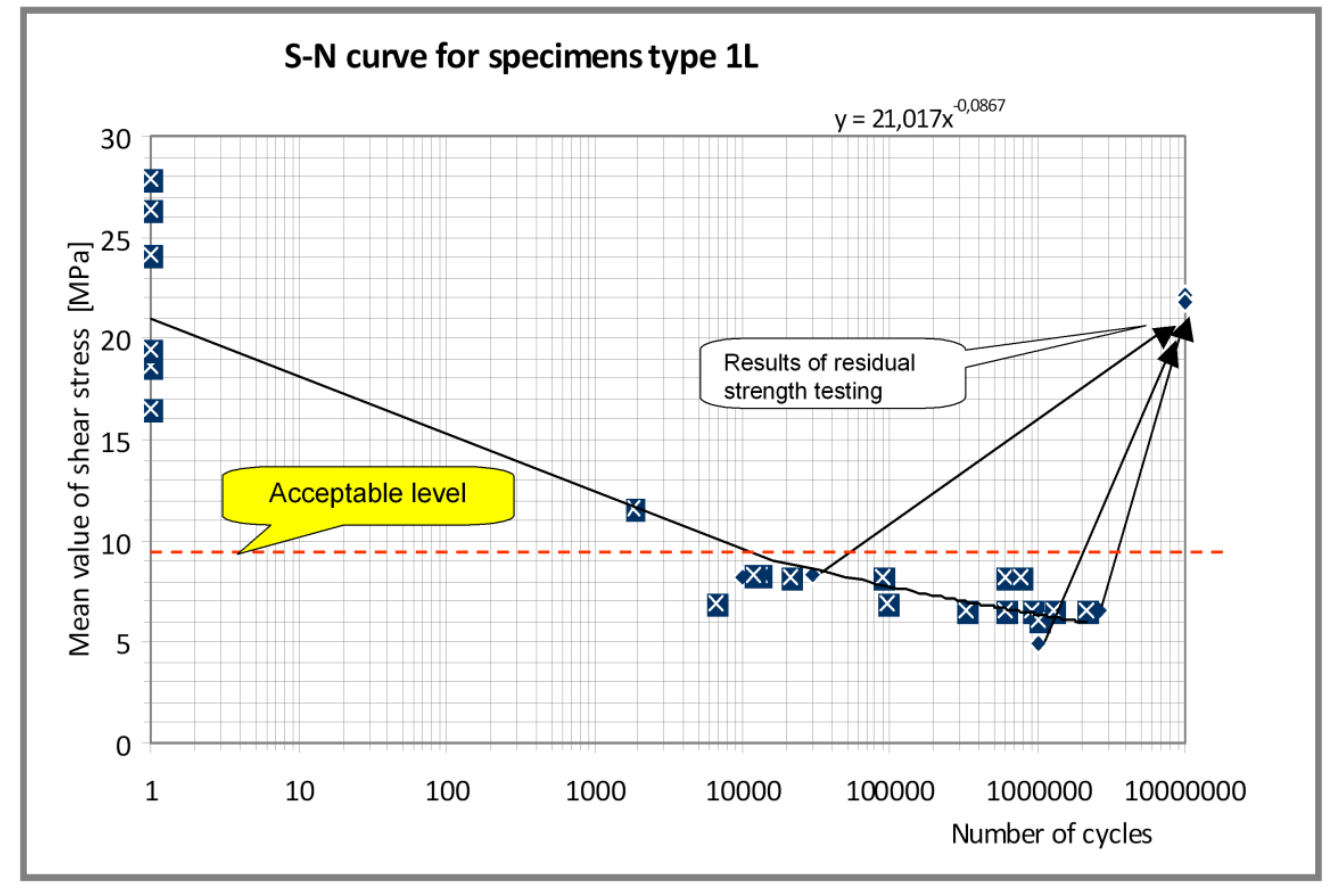

Fig. 7. S-N curve for single lap adhesive connection of metal and composite

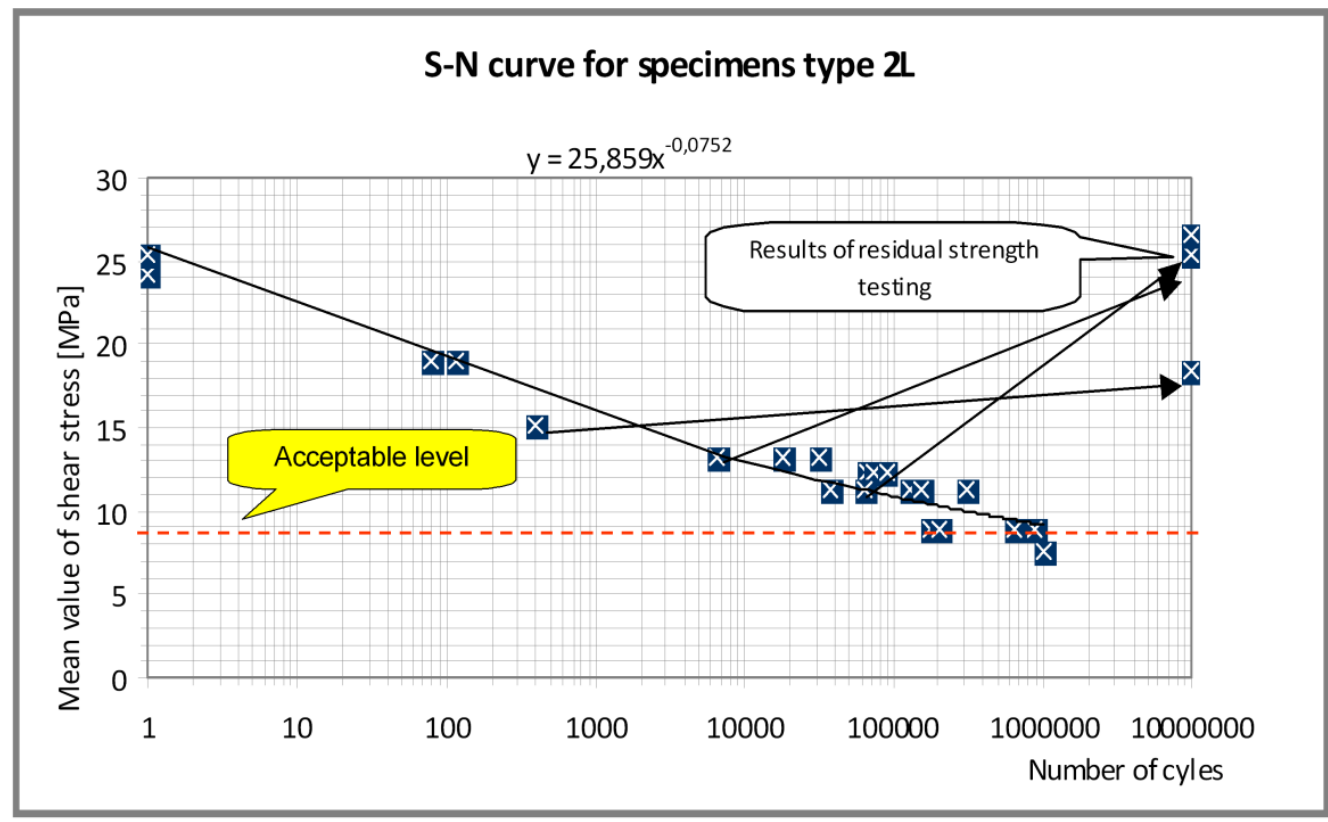

Fig. 8. S-N curve for double lap adhesive connection of metal and composite 
The second goal of the investigations was to observe the destruction process in the glued joints. For this purpose, there was made a theoretical analysis of the stresses in the glue connection (Fig.9). As the stiffness of metal and composite elements are different here, the edge of the glueconnection from the composite side is more loaded (Fig. 10), so one can expect that during the fatigue process the first damage will be observed exactly there.

$$
\begin{aligned}
& \text { Input data: } \\
& E_{1}:=2.1 \cdot 10^{11} \quad \text { - Young modulus of the } 1 \text { st element } \\
& E_{2}:=65 \cdot 10^{9} \quad \text { - Young modulus of the } 2 \text { nd element } \\
& G_{3}:=60 \cdot 10^{6} \quad \text { - G-modulus of the glue } \\
& \delta_{1}:=3 \cdot 10^{-3} \quad \text { - thickness of the } 1 \text { st element } \\
& \delta_{2}:=2.3 \cdot 10^{-3} \quad \text { - thickness of the } 2 \text { nd element } \\
& h:=0.2 \cdot 10^{-3} \quad \text { - thickness of the glue } \\
& l:=12.5 \cdot 10^{-3} \quad \text { - glue connection length } \\
& s:=25 \cdot 10^{-3} \quad \text { - width of the specimen } \\
& P \quad:=810 \quad .9 .81 \quad \text { - Load }[\mathrm{N}] \\
& \sigma_{10}:=\frac{P}{\delta_{1} \cdot s} \quad \sigma_{20}:=\frac{P}{s \cdot \delta_{2}} \quad \text { - stress in the glued elements outside the glue connection } \\
& \alpha:=\sqrt{\frac{\left(E_{1} \cdot \delta_{1}+E_{2} \cdot \delta_{2}\right) \cdot G_{3}}{E_{1} \cdot \delta_{1} \cdot E_{2} \cdot \delta_{2} \cdot h}} \quad \beta:=\frac{\delta_{1}}{\delta_{2}} \quad \gamma:=\frac{E_{2}}{E_{1}} \quad \varepsilon:=\frac{\delta_{1} \cdot E_{1}}{\delta_{2} \cdot E_{2}} \\
& \sigma_{1}(x):=\frac{\sigma_{20}}{\beta \cdot(\varepsilon+1)} \cdot\left(-\frac{\varepsilon+e^{-\alpha \cdot l}}{2 \cdot \sinh (\alpha \cdot l)} \cdot e^{\alpha \cdot x}+\frac{\varepsilon+e^{\alpha \cdot l}}{2 \cdot \sinh (\alpha \cdot l)} \cdot e^{-\alpha \cdot x}+\varepsilon\right) \\
& \sigma_{2}(x):=\frac{\sigma_{20}}{(\varepsilon+1)} \cdot\left(\frac{\varepsilon+e^{-\alpha \cdot l}}{2 \cdot \sinh (\alpha \cdot l)} \cdot e^{\alpha \cdot x}-\frac{\varepsilon+e^{\alpha \cdot l}}{2 \cdot \sinh (\alpha \cdot l)} \cdot e^{-\alpha \cdot x}+1\right) \\
& \tau_{x}(x):=\delta_{2} \cdot \sigma_{20} \cdot \frac{\alpha}{2 \cdot(\varepsilon+1) \cdot \sinh (\alpha \cdot l)} \cdot\left\lfloor\left(\varepsilon+e^{-\alpha \cdot l}\right) \cdot e^{\alpha \cdot x}+\left(\varepsilon+e^{\alpha \cdot l}\right) \cdot e^{-\alpha \cdot x}\right\rfloor
\end{aligned}
$$

Fig. 9. Mathematical model of adhesive connection [1] 


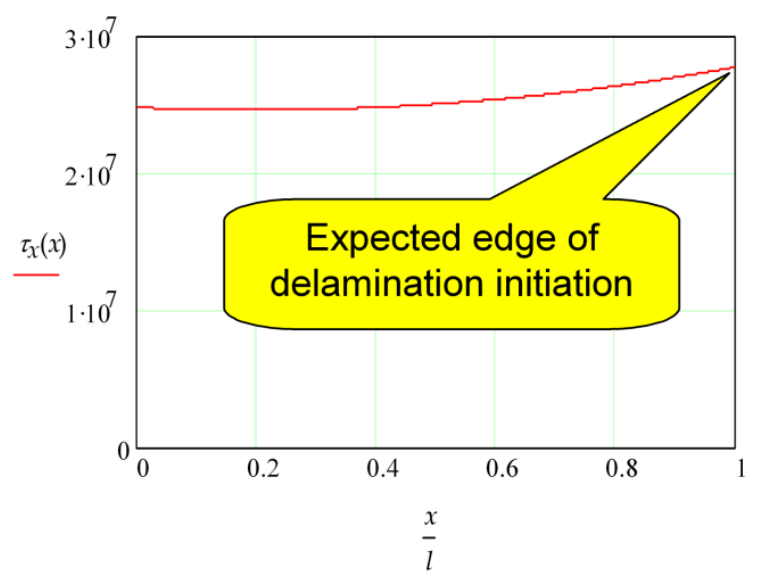

Fig. 10. Shear stress distribution in the adhesive layer

As a tool for this observation, there was prepared an ultrasonic scanner with a stand for immersion testing (Fig.11). The method applied was the "trough transmission" ultrasonic NDTmethod.

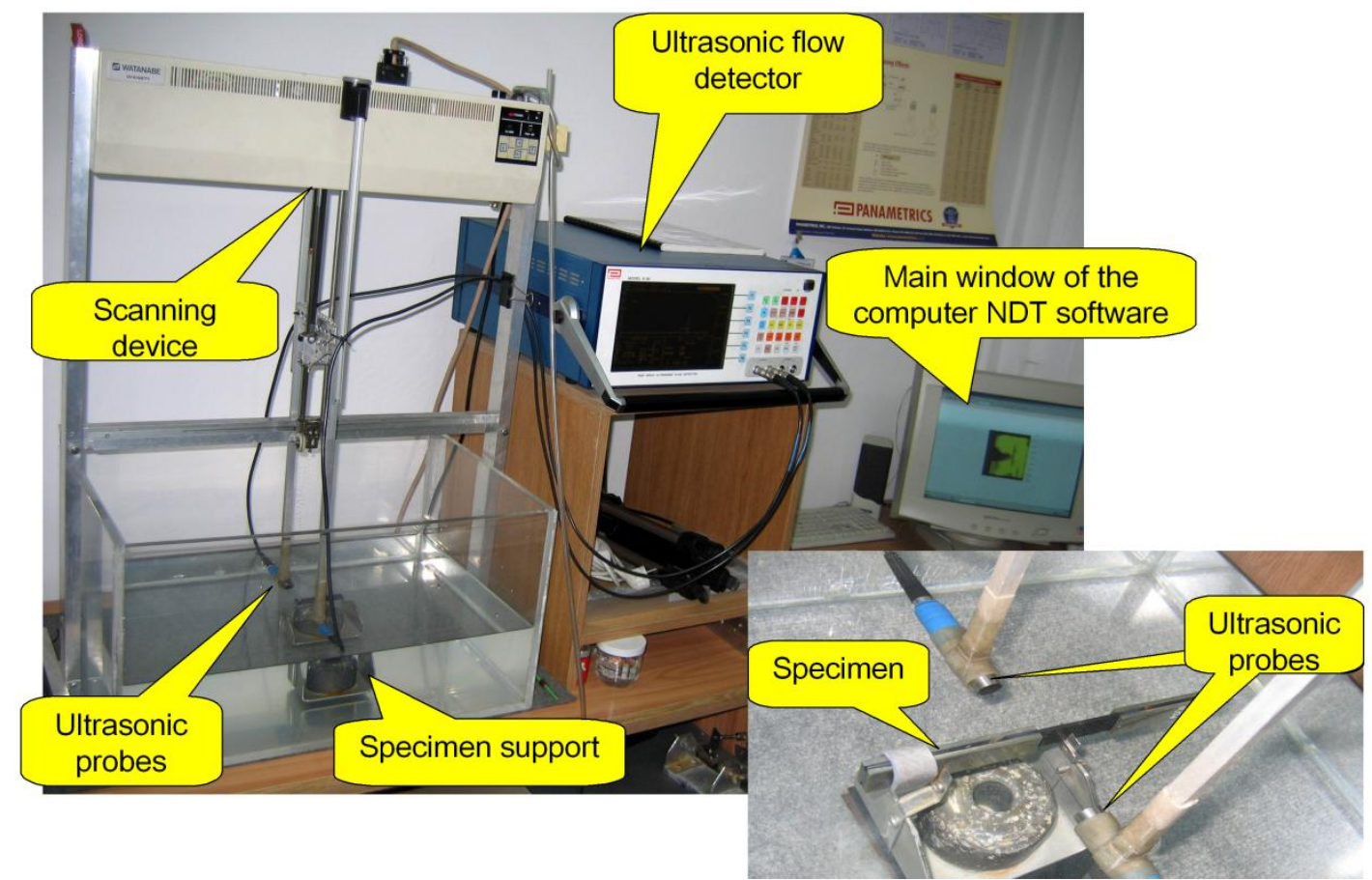

Fig. 11. NDT testing facilities

For the graphic presentation of the scanning results, the original software was used developed at the WUT [2]. The idea of the algorithm is explained in Fig. 12. As it is well known, the basic output from an ultrasonic flow detector is an A-scan obtained at a current point of tested specimen. It is possible to set the so-called "measurement gate" and to observe the amplitude of the signal in a chosen part of the A-scan, and to produce on this basis the 2-dimensional C-scans. It is the simplest way of generating the C-scan bitmaps. However, a much more effective method is to compare the whole scans by means of correlation function. This method is illustrated in Figure 13. In this case, A-scans made at the following scanned points of the specimen are compared with the template scan, which can be obtained from a specially chosen point of the same specimen. The maximum values of correlation function at the following scanned points are used in the software for making color C-skan bitmaps. 
Figure 14 presents an example of typical scans of the single lap specimen made at different stages of the fatigue test. All images in this figure are based on the amplitude in the measurement gate. What is very important at first glance: any delamination is visible on the edge of the glueconnection from the composite side, even at the advanced stage of the fatigue process.

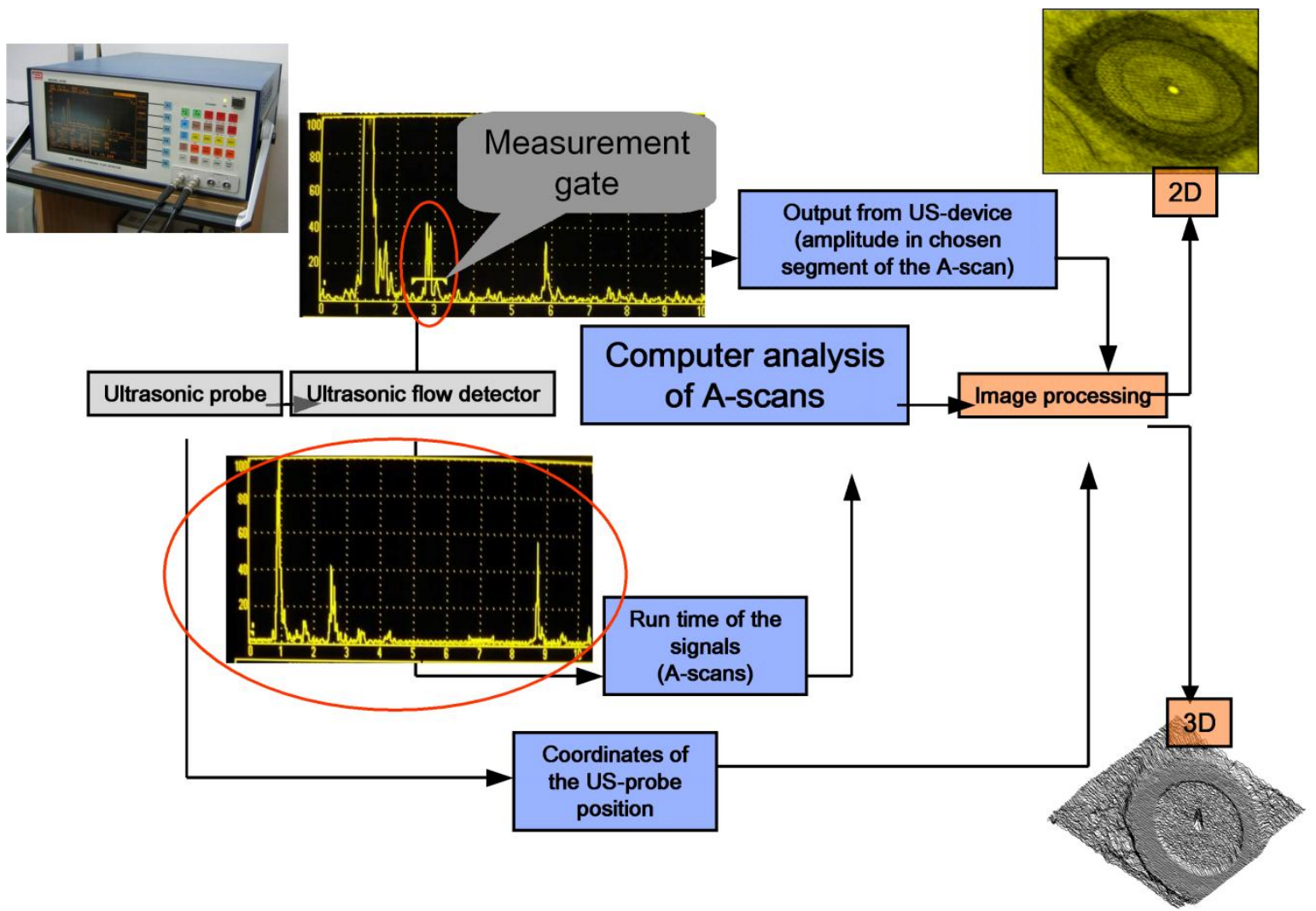

Fig. 12. Idea of images processing of ultrasonic inspection results

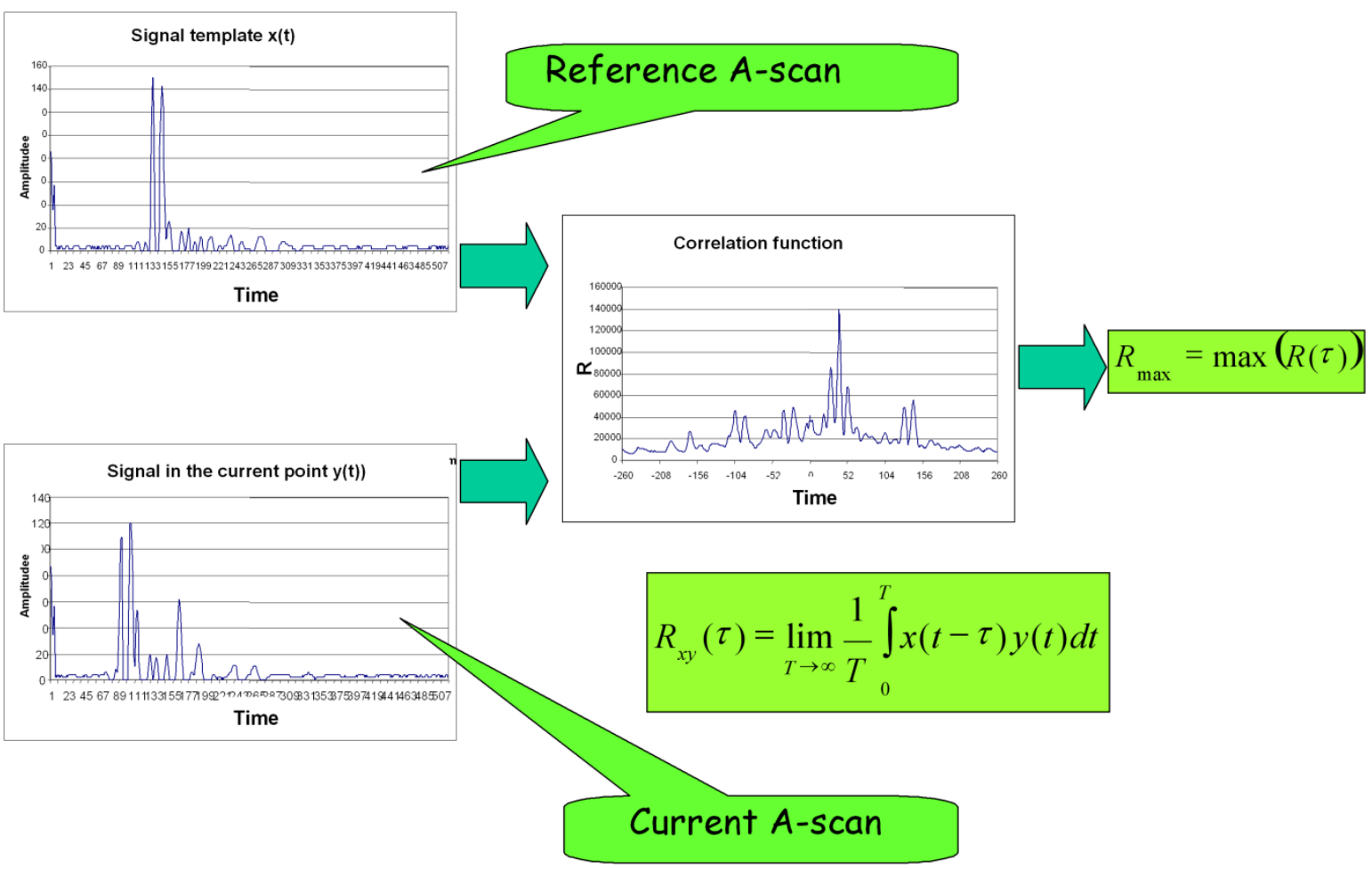

Fig. 13. Correlation function of A-scans and application values of correlation coefficients for processing the $C$-scan bitmaps 


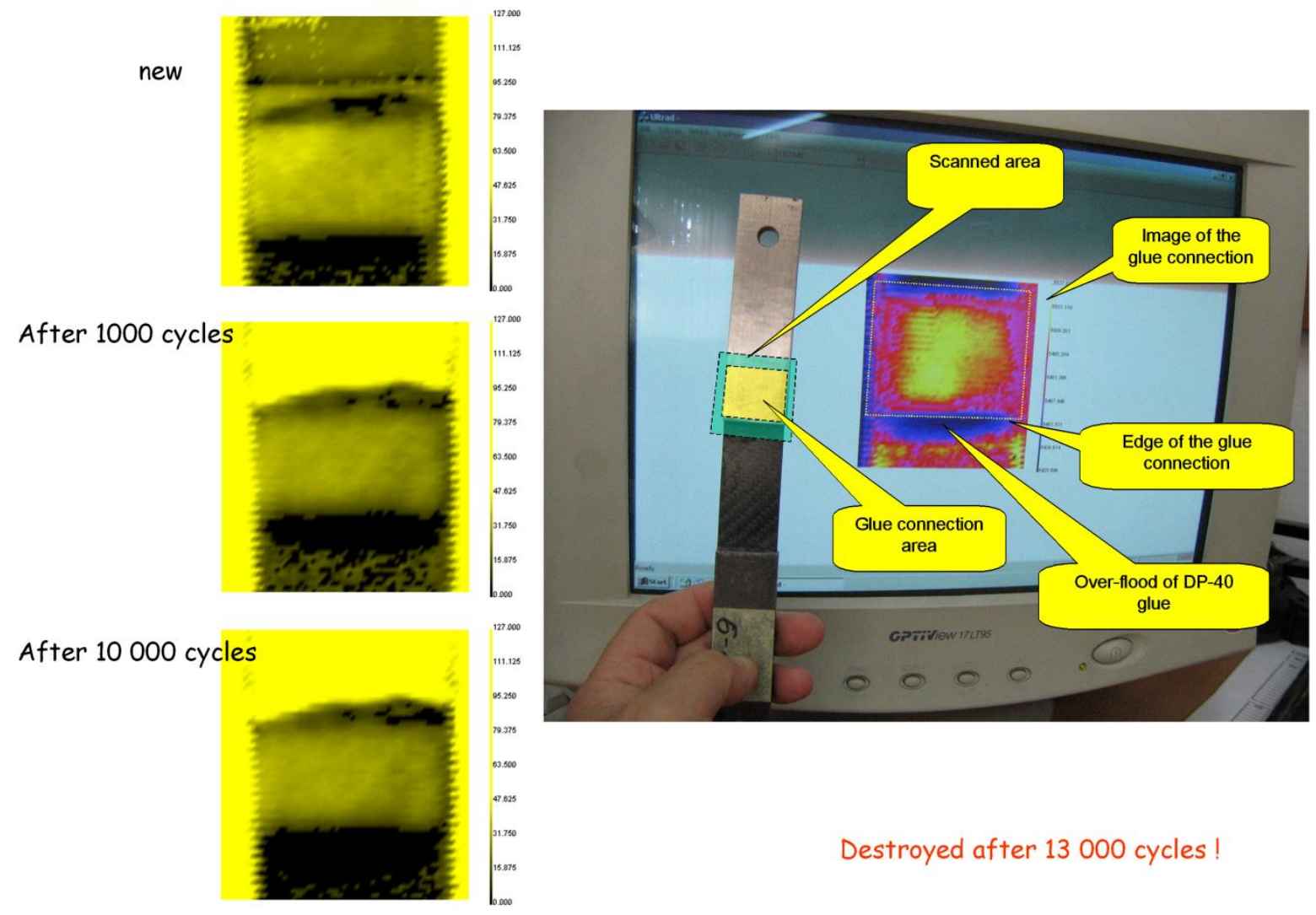

Fig. 14. C-scans based on amplitude in the measurement gate

Figure 15 presents the bitmaps of scanned specimen, obtained with correlation method.

Template made on composite

new

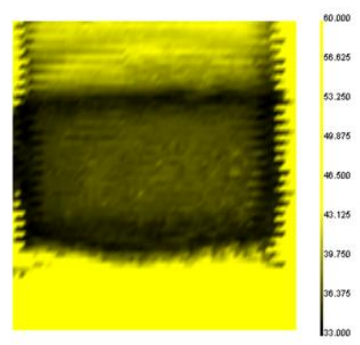

Template made on metal

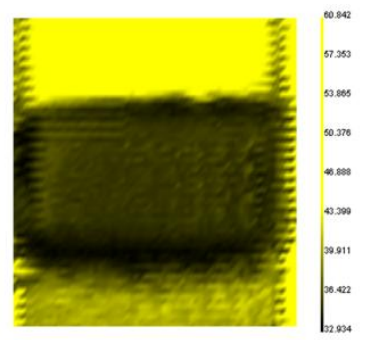

Template made on glue-connection

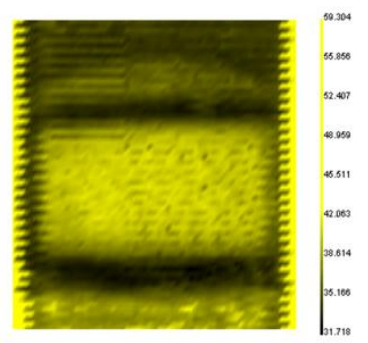

After 250000 cycles
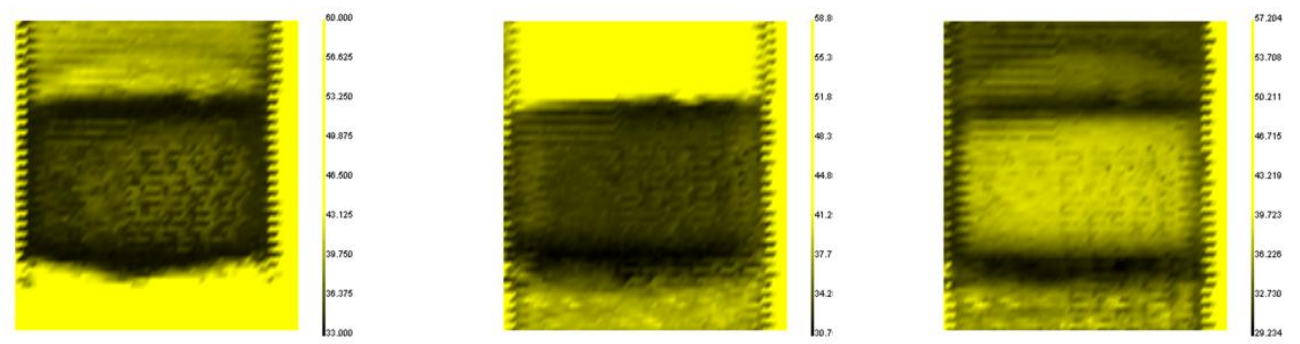

Destroyed after 612000 cycles !

Fig. 15. Typical C-scans obtained from correlation method 
In the case of Figure 16, the specimen was destroyed after 753 thousand cycles, while the last scanning was done after 750 thousand load cycles. Again, no delamination on the edge of the glueconnection from the composite side appears. Such a behavior was typical of the majority of tested specimens.
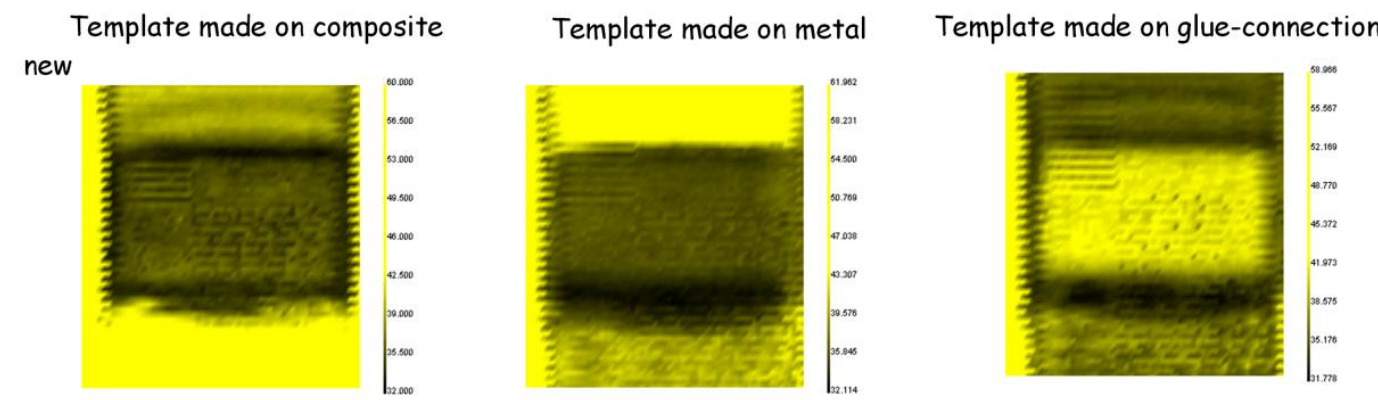

After 750000 cycles (just before destruction)
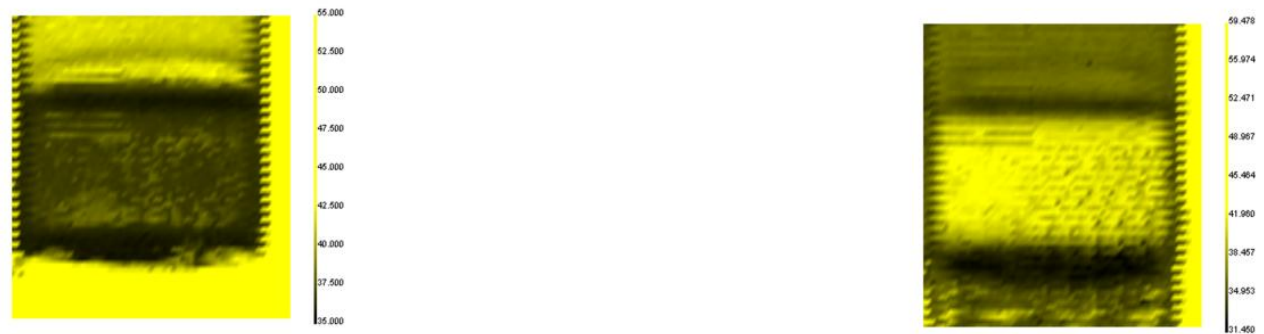

Destroyed after 753000 cycles!

Fig. 16. Images obtained from correlation method

Figure 17 presents very interesting case as the fatigue process of the specimen was stopped just before destruction. Only in this particular case, on the C-scans there are visible the delamination zones in the two opposite corners of the glue lap.

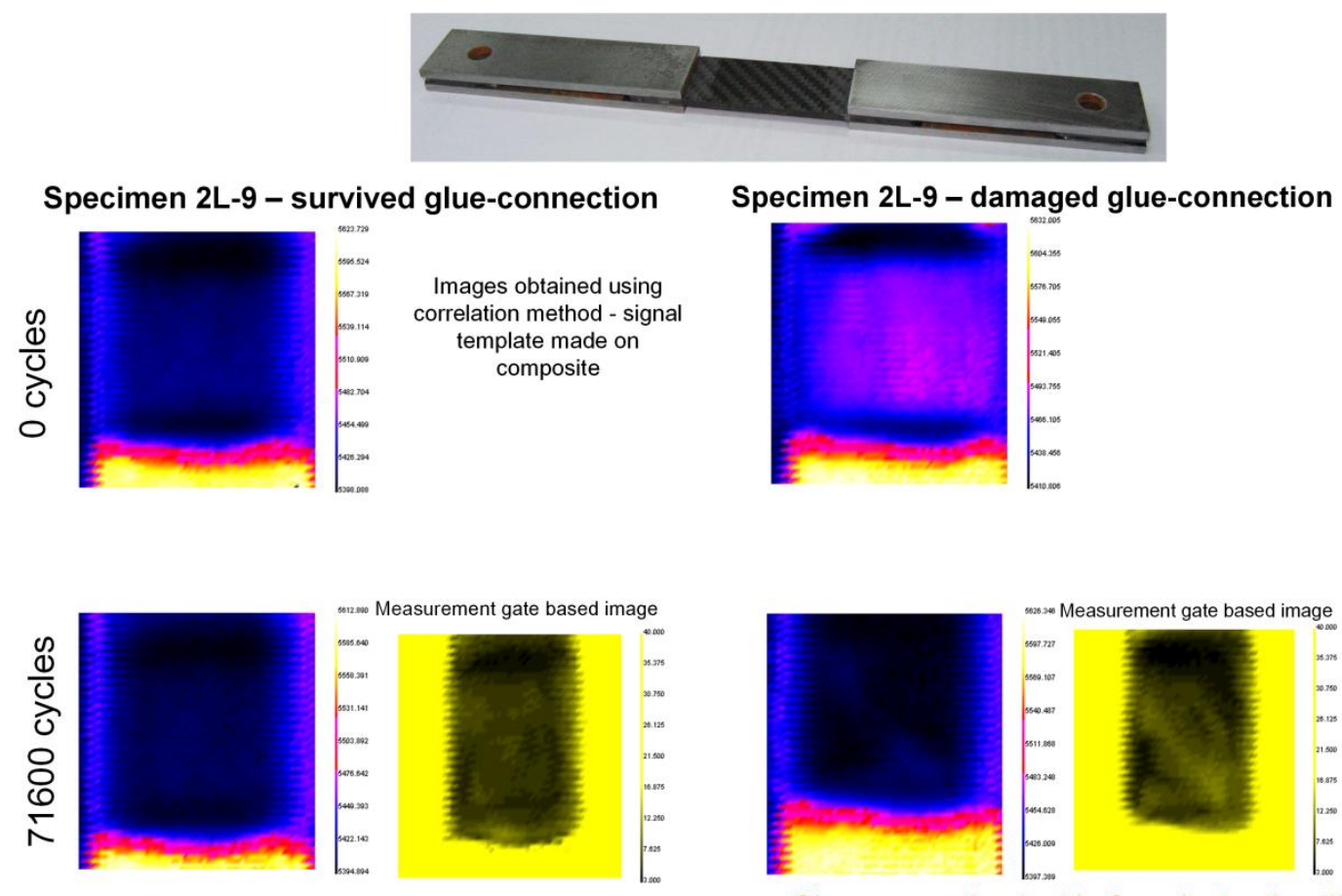

Glue connection just before destroying !!!

Fig. 17. Visible delamination zones just before specimen destruction 


\section{HEAT EFFECT IN FATIGUED GLUE CONNECTION}

One can ask how to detect that the fatigue life of a specimen is approaching an end? This question refers to another interesting finding of those investigations. It is a heat effect, caused by energy dissipation in the glued joint during cycle loading. To be able to observe this effect, small thermocouples were glued to some chosen points of the tested specimens. During the first test - the thermocouples were glued mainly to the top surfaces of the specimen, but for better accuracy of temperature measurement in the layer of the glue, the thermocouples were glued on the side-edge of the specimens in remaining tests (Fig. 19).

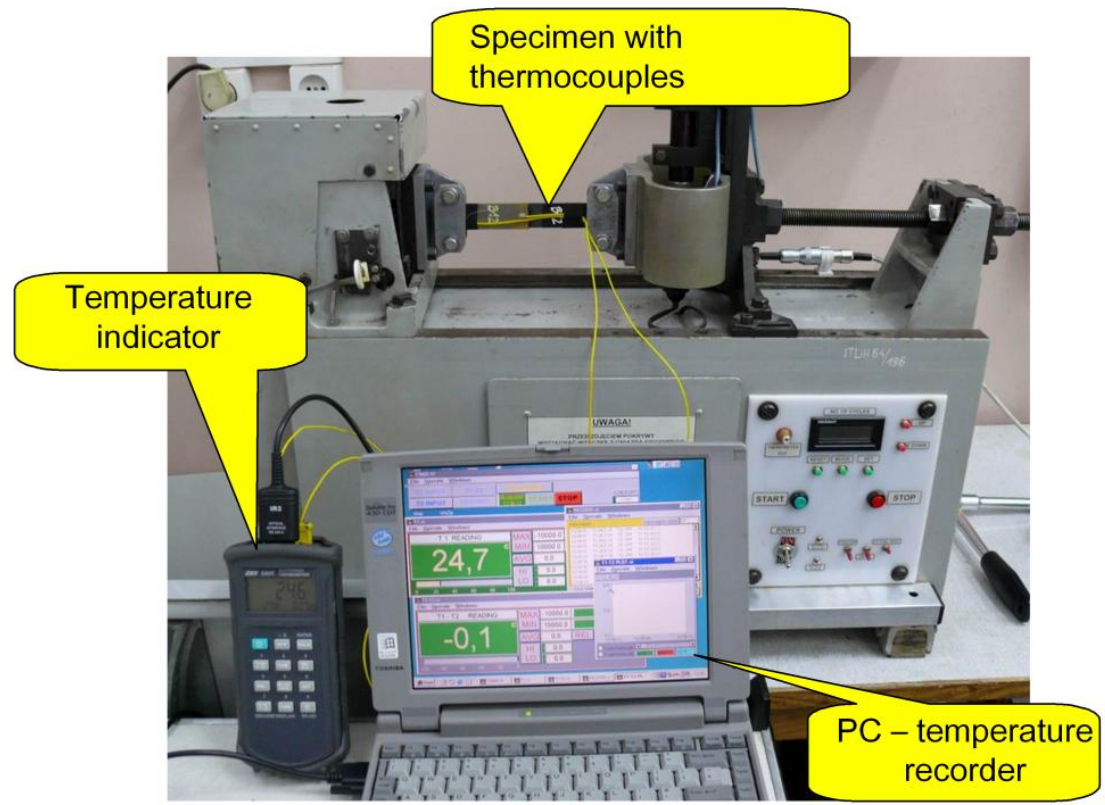

Fig. 18. Instrumentation for heat effect investigation
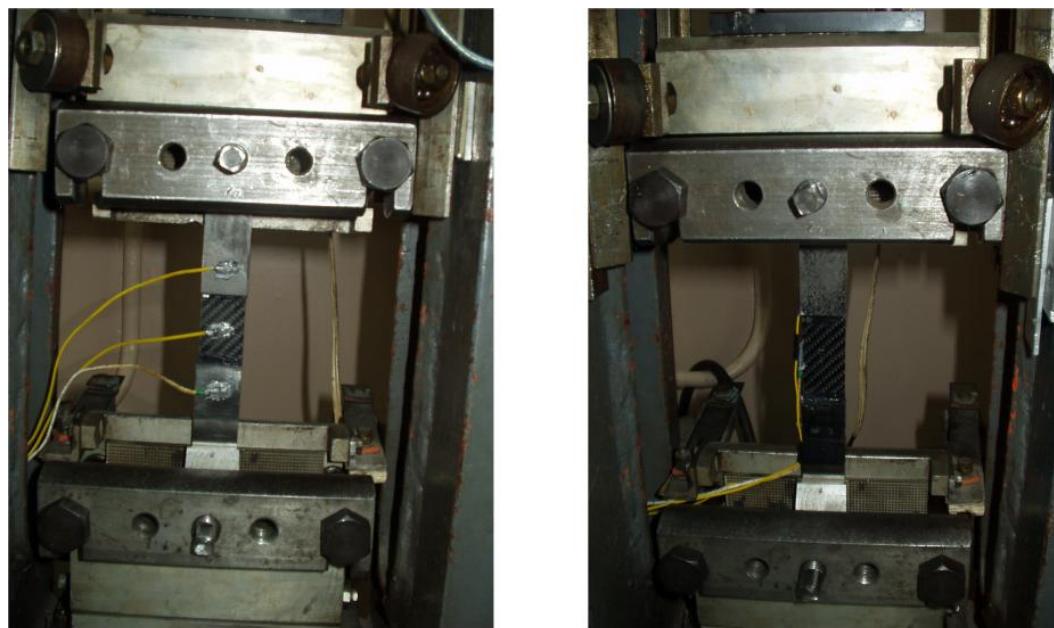

Fig. 19. Location of thermocouples in the double-lap joints

Figure 20 presents the temperature versus time charts for a chosen single-lap specimen. The upper chart was made at the early stage of fatigue testing while the lower chart was made at the final stage. Analysis of those charts reveals an interesting feature of the temperature gradient, which slowly increases when the glued joint is more fatigued. But just close to the moment of destruction of the glued joint - the temperature gradient rises very rapidly. This symptom was used for the prediction that the fatigue life of the specimen is close to an end. The same behavior was observed also during testing the double-lap joints. The temperature chart for a double-lap 
specimen is presented in Fig. 21. As it can be seen from the chart, the maximum temperature was obtained not before the destruction, but several cycles later. It was due to the inertia of the fatigue machine, which cannot be stopped rapidly, so some cycles are made on the damaged specimen, producing huge friction.
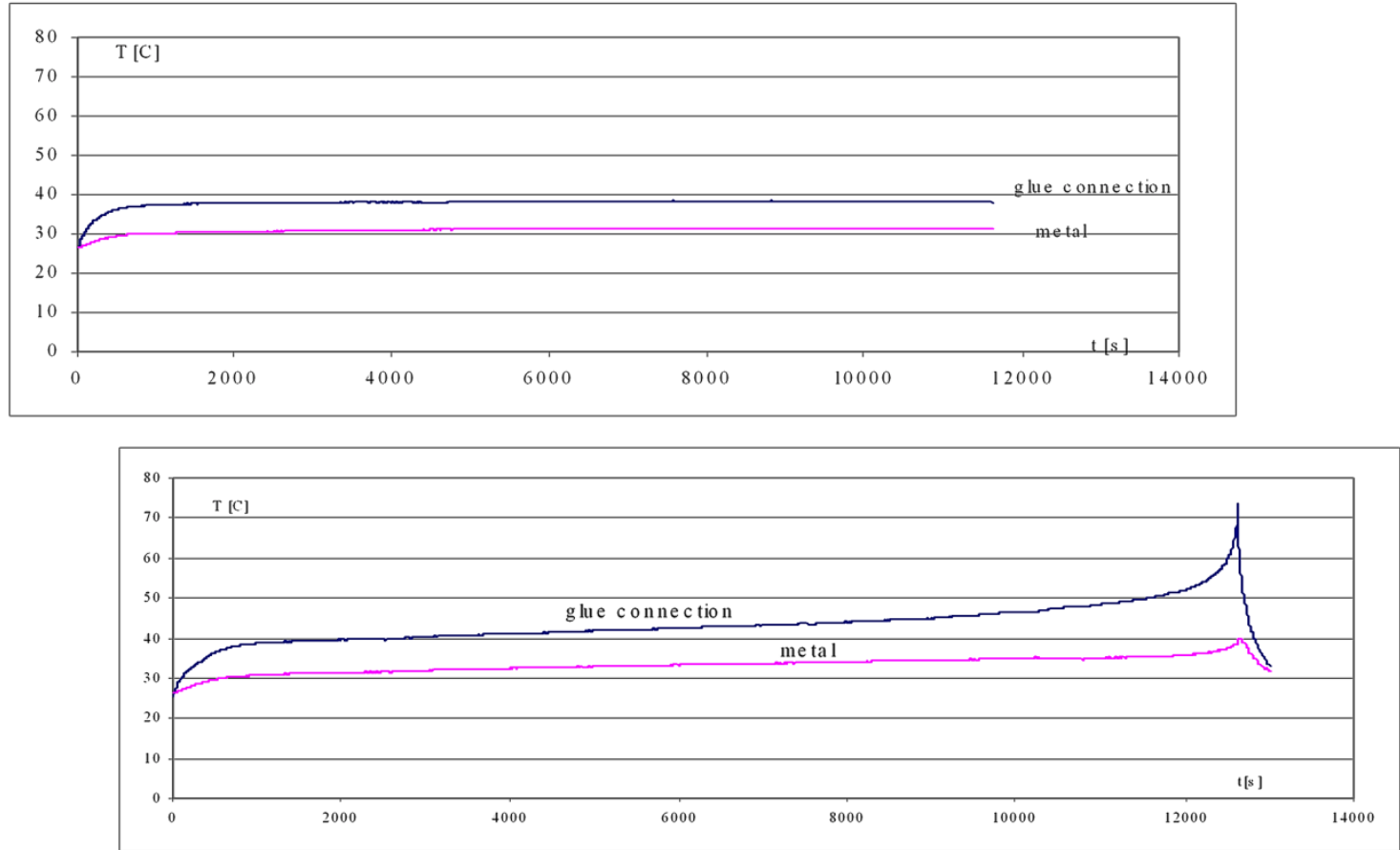

Fig. 20. Difference of temperature gradients for early and final phases of fatigue process of a single-lap specimen

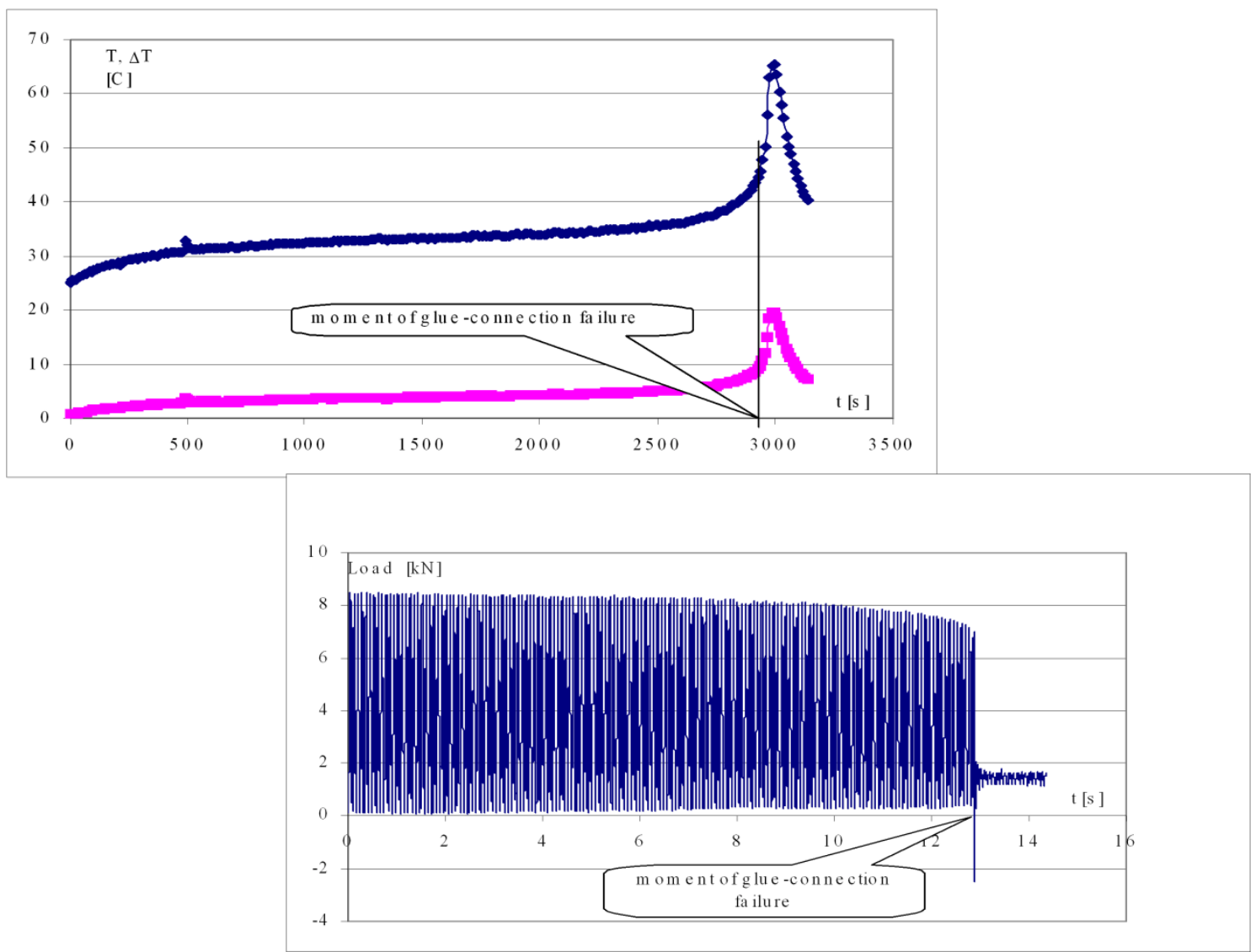

Fig. 21. Heat effect investigation for a double-lap specimen 
Figure 22 contains some images of the specimen made by an infra-red camera, which confirm that the temperature in the glue-lap is increasing very significantly before the specimen destruction. It was an extra test, and for speeding up the fatigue effect - the $\mathrm{R}$ value was changed to -1 for this particular specimen.

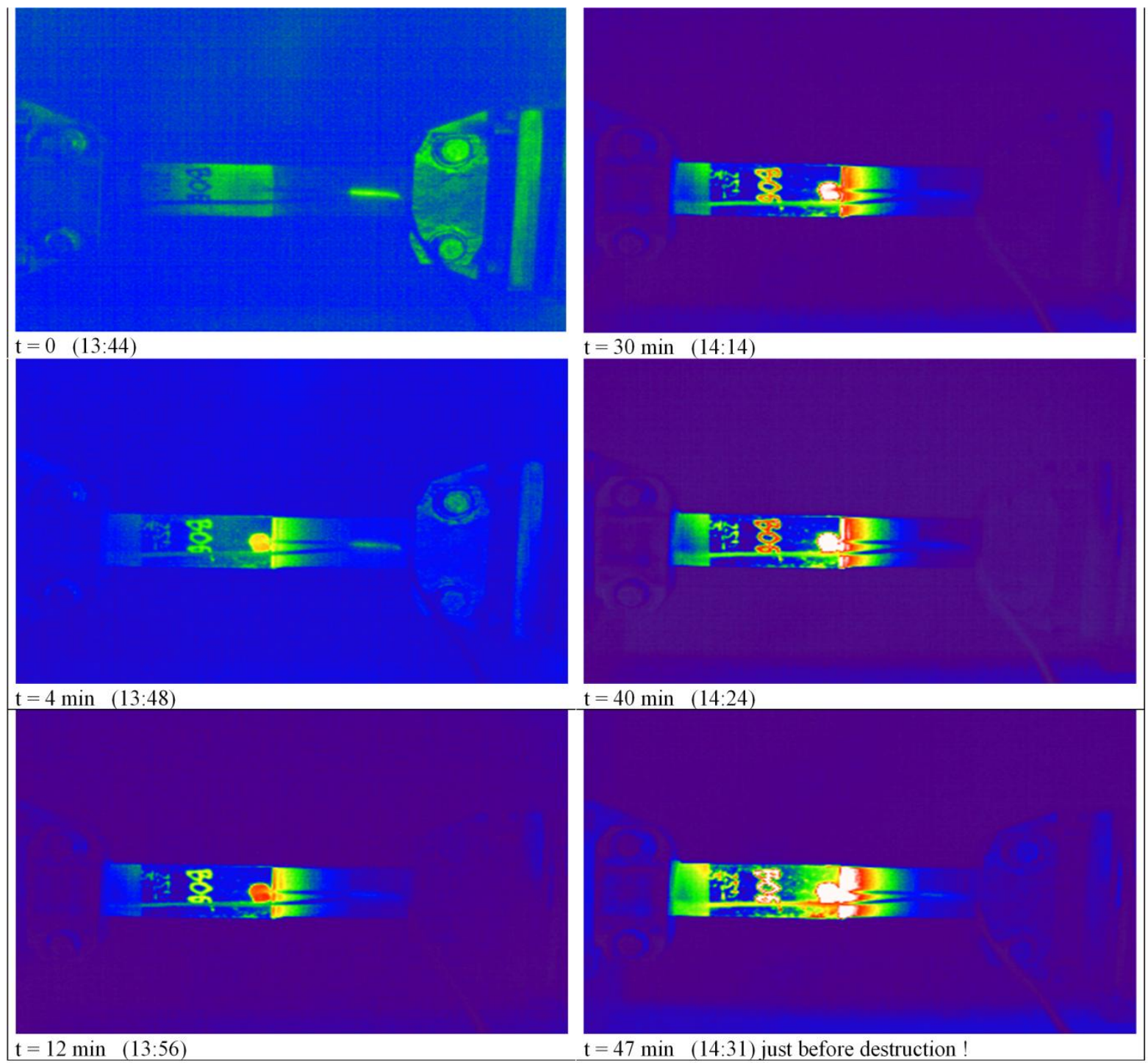

Fig. 22. Thermo-vision images taken during the fatigue tests

\section{STIFFNESS DETERIORATION}

The process of stiffness deterioration just before specimen destruction - was observed also by means of a fast camera. For this purpose, 3 white line segments were marked on the side edge of the specimen. Fig. 23 shows the set of image couples made for minimum load and for maximum load. The index in the bottom of each picture indicates the sequence number of the picture.

At the beginning of the fatigue test the displacement of glued elements was insignificant and difficult to detect. But near the end of fatigue life the displacement was very visible. The last picture is made exactly at the moment of specimen destruction. Figure 24 contains the chart with load history recorded in the last phase of fatigue. The effect of stiffness deterioration is clearly visible there. 


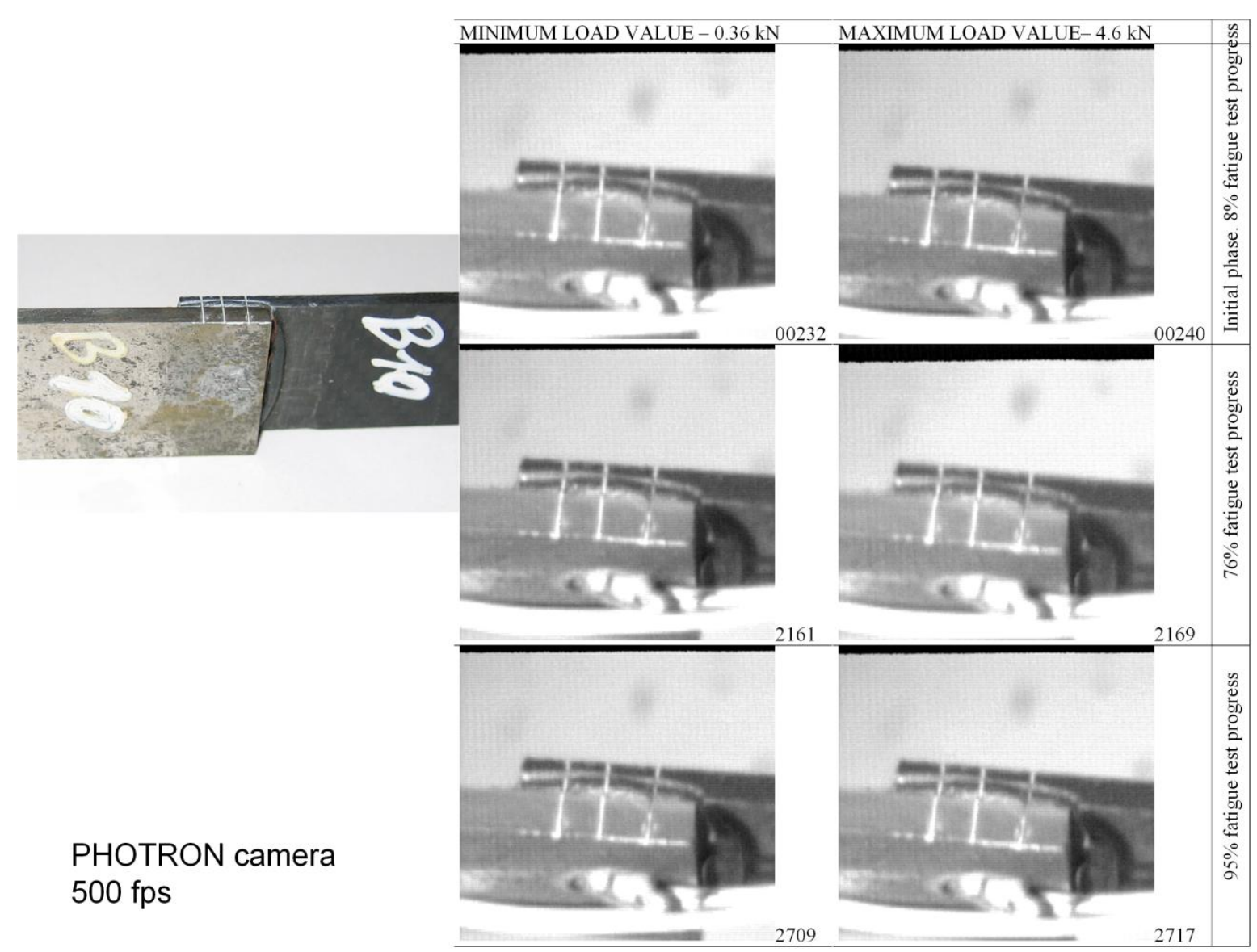

Fig. 23. Early phase of fatigue test

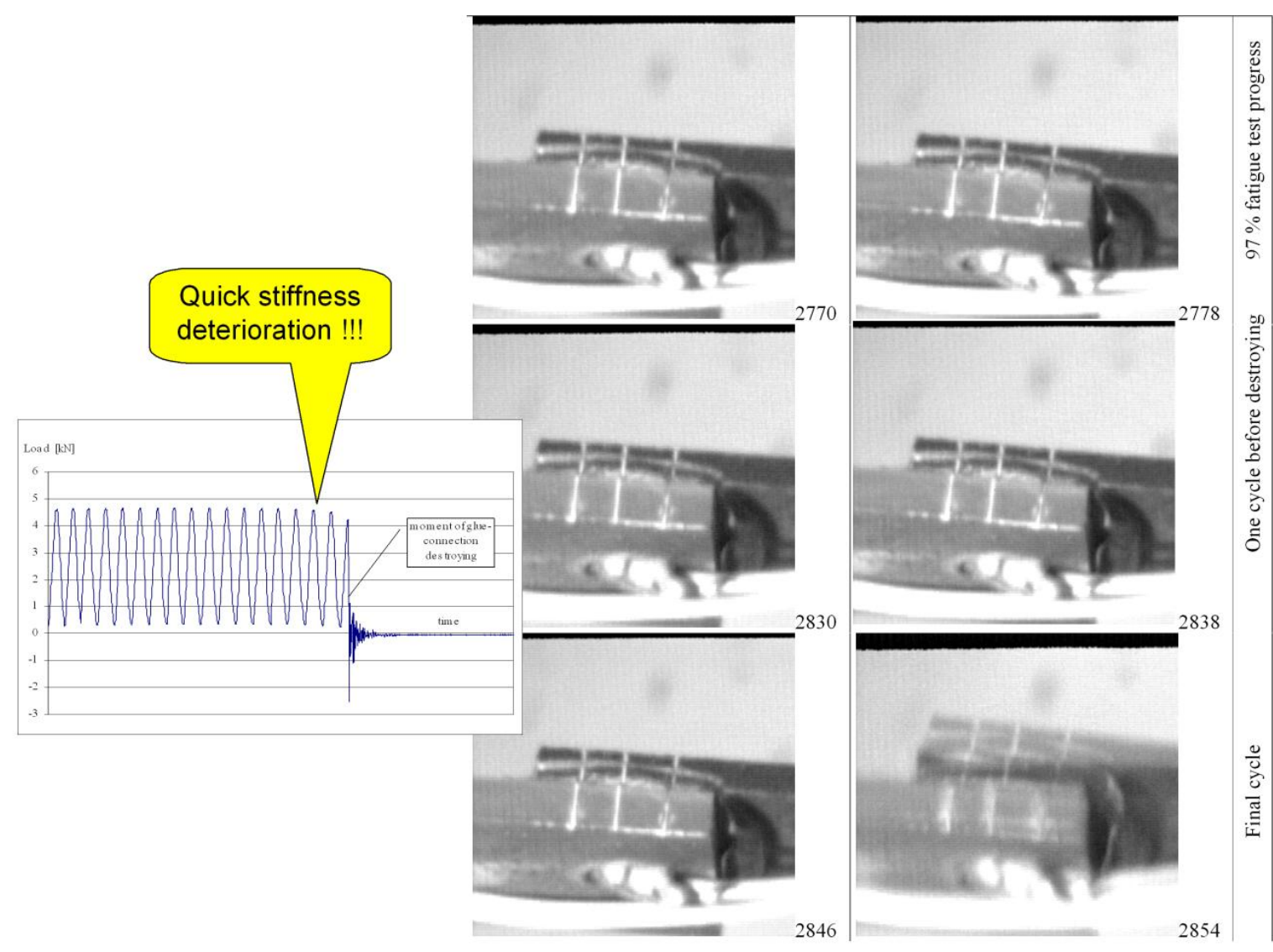

Fig. 24. Final phase of fatigue test 


\section{FRACTURE MODES}

Two fracture modes were observed during the tests for both adhesives WK-3 and DP-490: disadhesion and discohesion (Fig. 25).

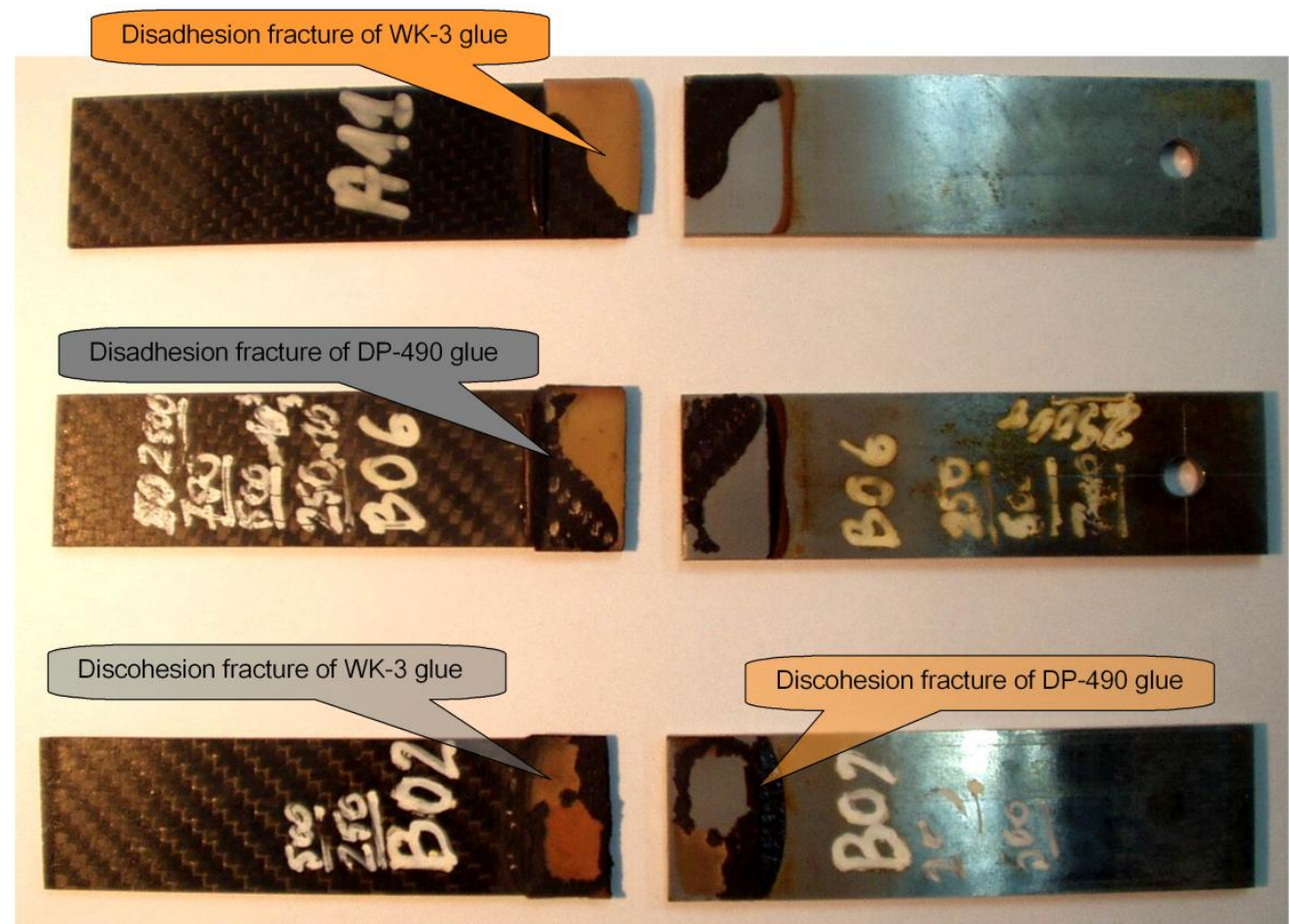

Fig. 25. Fracture modes of the single-lap specimens

Figures 26 presents microscopic images of typical disadhesion fracture, and typical discohesion fracture of the WK-3 glue.

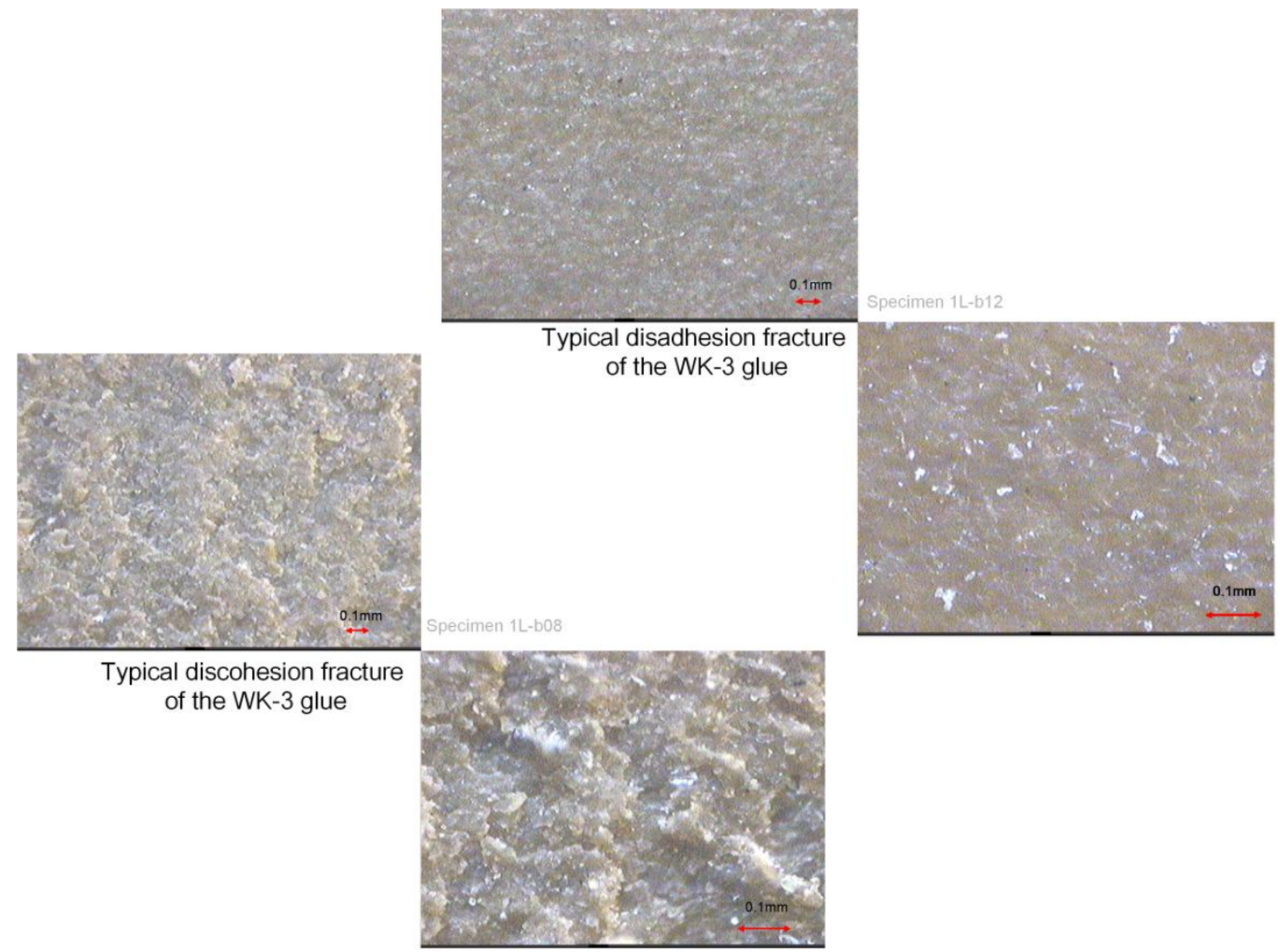

Fig. 26. Microscopic pictures of the WK-3 glue fracture 
Figure 27 concerns the fracture of DP-490 glue. The upper pictures show the difference between fracture modes for a static strength test and for a fatigue strength test. But the most important are the pictures at the bottom, because they contain the answer to the question why the expected growth of delamination from the composite side edge of glued-lap (as it was in the physical model) was not observed in practice, but instead there was observed rather equal fatigue deterioration of the glue structure in the whole area of the glued joint. As it can be seen in the last picture- the reason for it are small air bubbles inside the structure of the DP-490 glue. Each air bubble became the source of fatigue damage propagation, and the damage developed almost equally in whole volume of the glue-layer.

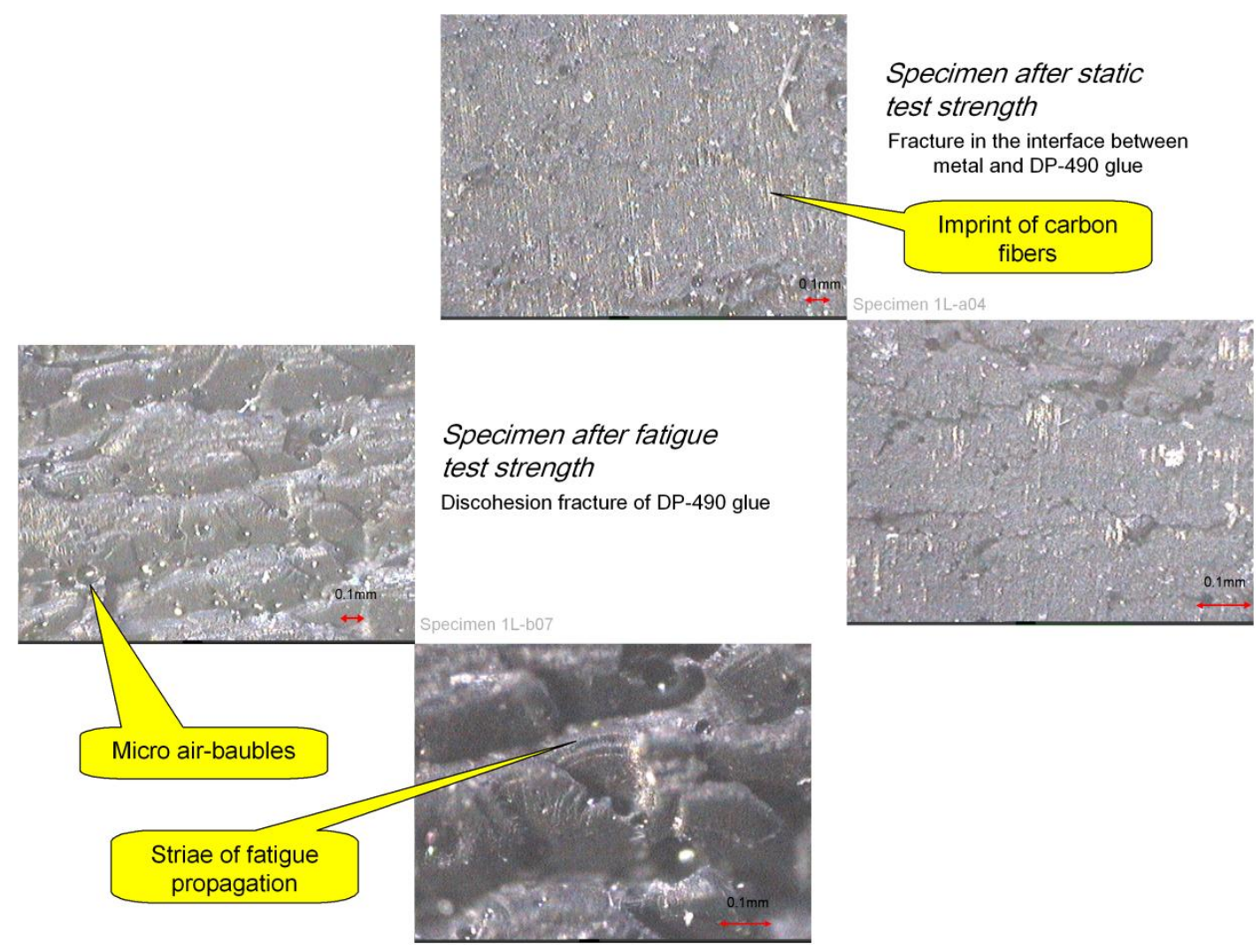

Fig. 27. Microscopic pictures of the DP-490 glue fracture

\section{CONCLUSIONS}

The following features were observed for glued joints considered in the presentation:

- Double-lap glue joints reveal about 100 times higher fatigue life than single-lap glue joints.

- The fatigue process takes place almost equally in the whole area of the glued joints.

- Thermal gradient increases with fatigue advancement. This could be used as an important parameter for diagnostics purposes.

Acknowledgements: The investigations presented in the paper were a part of larger scientific project lead by professor Tadeusz Niezgoda ot the Military University of Technology in Warsaw. The author would like to express warm thanks for wise supervising and financial support.

\section{REFERENCES}

[1] Д. А. КАРДАШОВ (1960). КЛЕИ И ТЕХНОЛОГИЯ СКЛЕИВАНИЯ - СБОРИК СТАТЕЙ. ОБОРОНГИЗ, МОСКВА.

[2] Rodzewicz, M. \& Czerwinski, G. (2009). Some investigations into ultrasonic diagnostics aplicability for composite structure. Diagnostyka. 4(52), $61-64$. 